\title{
Sagittal sinus thrombosis: An unusual presentation of tubercular adenitis
}

\author{
Tahir Majeed*, Fahad Shafi, Aadil Bashir Rather, Abid Kuchay and Sahil Hassan \\ Sher-i-Kashmir Institute of Medical Sciences, Department of General Medicine, Soura, Srinagar, Jammu and Kashmir 190011, India
}

\begin{abstract}
We report a case of a young female who presented to us with multiple episodes of seizures with imaging revealing sagittal sinus thrombosis due to tubercular adenitis. To our knowledge this sagittal sinus thrombosis due to tubercular adenitis has not been reported in medical literature.
\end{abstract}

\section{Case}

We report a case of 24 years old married homemaker from rural background with low economic status presenting to us with multiple episodes of abnormal body movements from past 3 days in form of Generalised Tonic Clonic Movements (GTCS) with last episode occurring 30 minutes prior to reception in Accident and Emergency (A\&E). On examination patient was confused drowsy and responding poorly to commands. She was hemodynamically stable and maintaining oxygen saturation of $94 \%$ on room air. She was afebrile. Her husband gave history of similar episodes of confusion remaining for two to three hours every time she suffered an abnormal body movement in past 3 days with patient regaining orientation in terms of place person and time in between. There was also family history of Pulmonary Tuberculosis and evening rise of temperature associated with constitutional symptoms. There was no history of trauma, contraceptive use or any focal neurological deficit. Rest of the exam was normal. NCCT head was done which revealed hypodensities in bilateral frontal region with hyper dense sagittal sinus raising possibility of Sagittal sinus thrombosis.MRI brain was done which confirmed the suspicion and revealed acute infarcts in bilateral frontal regions with evidence of sinus thrombosis (suggestive of venous infarcts) as shown in Figure 1-3. Patient was managed with antiepileptic drug Levetiracetam and therapeutic anticoagulation was achieved with warfarin (Figure 1-3).

On thorough examination, patient was found to have left cervical

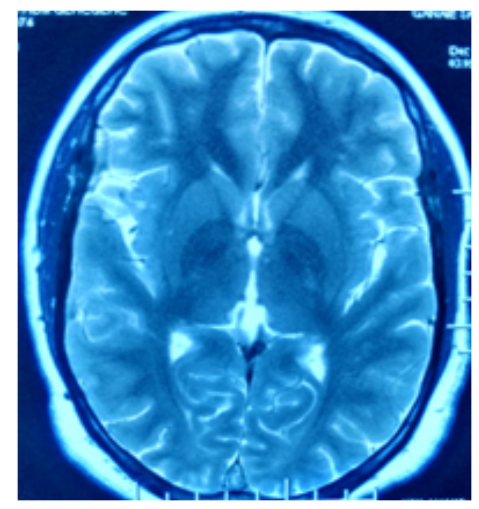

Figure 1. Axial T2 image showing loss of flow void of superior sagittal sinus. lymphadenopathy. Lymph nodes were firm to hard in consistency, mobile and matted. Complete blood counts revealed anaemia ( $\mathrm{Hb}$ $=9 \mathrm{~g} / \mathrm{dl}$ ) with high ESR $(52 \mathrm{mmhr})$. Rest of cell lines were normal. PBF revealed Normocytic Normochromic cells and did not show any abnormal cells. Blood chemistry was within normal limits. Thrombotic profile (protein S, protein C, AT III, APLA, Factor V Leiden mutation, G20210A mutation) and ANA were negative. Fibrinogen levels, coagulogram was normal. The immunologic function revealed a normal immunoglobulin's (IgG: $1920 \mathrm{mg} / \mathrm{dL}$, IgM: $495 \mathrm{mg} / \mathrm{dL}$ ), immune complexes $(15.43 \mathrm{U} / \mathrm{ml})$ and $\mathrm{C} 3$ and C4 levels $(\mathrm{C} 3: 78.3 \mathrm{mg} /$ $\mathrm{dL}, \mathrm{C} 4: 11.9 \mathrm{mg} / \mathrm{dL}$ ). Septic screen was sterile. Sputum analysis and chest X-ray was normal but Tuberculin skin test was positive. CSF was clear with an opening pressure of $260 \mathrm{mmHg}$ of $\mathrm{H}_{2} \mathrm{O}$. Cells, protein,

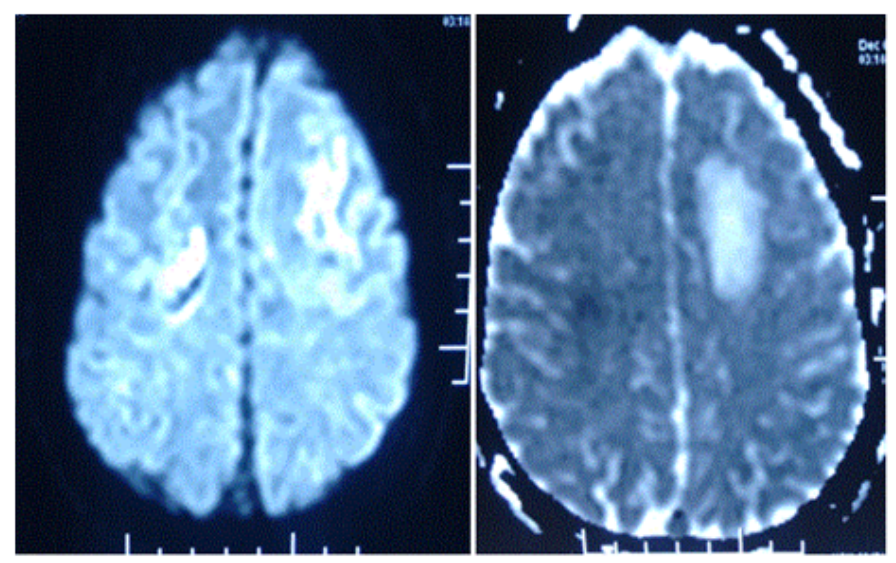

Figure 2. DWI (b value 1000) with corresponding ADC map revealing infarcts in frontal regions with associated vasogenic edema.

Correspondence to: Tahir Majeed, Sher-i-Kashmir Institute of Medical Sciences, Department of General Medicine, Soura, Srinagar, Jammu and Kashmir 190011, India, Tel: +91-9858892740; E-mail: tahirmajeed34@yahoo.com

Key words: tubercular adenitis; sagittal sinus thrombosis

Received: December 11, 2016; Accepted: December 26, 2016; Published: January 02, 2017 


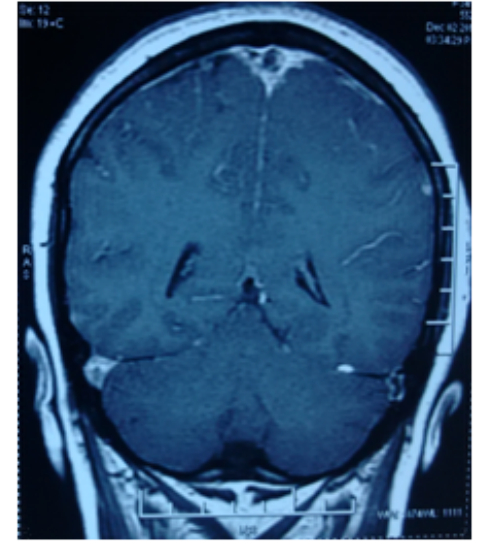

Figure 3. Post contrast T1 sagittal image revealing non-enhancing filling defect in superior sagittal sinus (empty delta sign).

sugar, LDH were within normal limits. Culture and Xpert MTB/RIF of CSF was negative. CECT chest abdomen and pelvis was normal however contrast imaging of neck showed multiple enlarged matted cervical nodes bilaterally with some showing central cystic changes. Excision biopsy of lymph node showed granulomas with areas of caseous necrosis without any visible AFB. However, Xpert MTB/RIF and culture from biopsied tissue was positive for tuberculosis. Patient was started on Anti tubercular therapy.

\section{Discussion}

Cerebral venous thrombosis (CVT) could be primary or secondary, which could be either septic or aseptic. Septic CVT is due to bacterial, fungal and parasitic infection. The common causes of aseptic CVT are pregnancy, puerperium, use of oral contraceptives, dehydration, cyanotic heart disease and Behcets disease. To our knowledge, Tuberculosis adenitis as a cause of aseptic CVT has not been reported before in literature. Both systemic and local factors play a role. Pathogenesis of aseptic CVT is either stasis of blood, as the intracranial sinus is a valve less low pressure system or more importantly a hypercoagulable state. This includes an increased number of platelets, [1] increase in platelets adhesiveness, [1,2] hyperfibrinogenemia [3-5] and decrease in fibrinolysis [1,3]. Reactive thrombocytosis has been reported in pulmonary tuberculosis [6-8]. Baynes, et al. showed in a small number of patients with pulmonary tuberculosis, an increased platelet count and increased platelet aggregability [7]. They attributed this hyperaggregability to a simultaneously increased reactive protein which has a proaggregating property. Sarode, et al. [9] found significant hyperaggregation in $88 \%(38 / 43)$ patients with intestinal tuberculosis. It has been established that severe tuberculosis can be responsible for a transitory hypercoagulable state $[10,11]$. Turken, et al. showed that patients with active pulmonary tuberculosis displayed thrombocytosis and increased fibrinogen, factor VIII, and plasminogen activator inhibitor 1 plasma levels, associated with depressed antithrombin III and protein C levels in the first month of treatment, resulting in activated coagulation and inhibited fibrinolysis [10]. All these modifications probably result from the inflammation cascade triggered by the chronic infection, as shown in several other acute infections [12-14]. Indeed, several experimental studies have shown that proinflammatory cytokines (interleukin 1, interleukin 6 , tumor necrosis factor $\alpha$ ) are produced during the acute phase of Mycobacterium tuberculosis infection, either by peripheral blood mononuclear cells [15], or bylung, lymph node, and spleen macrophages interacting with mycobacterial products $[16,17]$. These cytokines induce the production of various acute inflammation phase proteins and coagulation factors by hepatocytes, resulting in a hypercoagulable state $[18,19]$. It has also been shown that, in vitro, M. tuberculosis induces the expression of a tissue factor in monocytes, macrophages, that is, a primary activator of the clotting cascade [20,21]. Local factors may also induce the thrombosis of vessels. Organ infection can trigger local thrombosis, as observed in Lemierre disease (tonsillar abscess complicated by jugular vein thrombosis and lung embolism), possibly due to endothelial cell alteration and adhesion molecule expression [22]. In addition, active tuberculosis may mechanically favor local blood stasis: venous compression by retroperitoneal lymph nodes may result in proximal thrombosis, as reported in patients with extra pulmonary tuberculosis [23]. However predominant role seems to be of systemic hypercoagulable state rather than local factors as studied by Charlotte Dentan, et al. who did not find any predominant link between localization of tuberculosis and thrombosis.

\section{Conclusion}

TB causing thrombosis presenting as DVT and PE has been suggested by various case reports and case series however tubercular adenitis with CVT has not been reported in medical literature before. The aim of this report is to consider this entity in all patients of $\mathrm{TB}$ who present with or develop neurological manifestations during course of treatment. Prophylactic anticoagulation in high risk patients having $\mathrm{TB}$ is debatable and may be considered with risk benefit ratio to avoid thrombosis and it sequale.

\section{References}

1. Bansal BC, Gupta RR, Prakash C (1980) Stroke during pregnancy and puerperium in young females below the age of 40 years as a result of cerebral venous/venous sinus thrombosis. Jpn Heart J 21: 171-183.[Crossref]

2. Chopra JS, Prabhakar SK, Cas KC (1979) Stroke in the young in North-West India. In: Greenhalgh M, Rose FC (Eds) Progress in Stroke Research(1st Edn). Pitman Medical Bath pp: 217-235.

3. Srinivasan K (1983) Cerebral venous and arterial thrombosis in pregnancy and puerperium. A study of 135 patients. Angiology 34: 731-746.[Crossref]

4. Girolami A, Pardatscher K, Scanarini M, Job I, Patrassi G (1980) Clotting changes in two patients with longitudinal sinus thrombosis. Haemostasis 9: 71-78.[Crossref]

5. Girolami A, Ratilio A, Gerosa M (1991) Further studies on clotting changes in patients with cerebral sinus thrombosis. A case with thrombosis of right transverse sinus. Folia Haematol 108: 597-601.

6. Bannerman RG (1924) Blood platelet count in pulmonary tuberculosis. Lancet 1924 593-595.

7. Baynes RD, Bothwell TH, Flax H, McDonald TP, Atkinson P, et al. (1987) Reactive thrombocytosis in pulmonary tuberculosis. J Clin Pathol 40: 676-679.[Crossref]

8. Morris CD, Bird AR, Nell H (1989) The haematological and biochemical changes in severe pulmonary tuberculosis. Q J Med 73: 1151-1159.[Crossref]

9. Sarode R, Bhasin D, Marwaha N, Roy P, Singh K, et al. (1995) Hyperaggregation of platelets in intestinal tuberculosis: role of platelets in chronic inflammation. $\mathrm{Am} \mathrm{J}$ Hematol 48: 52-54.[Crossref]

10. Turken O, Kunter E, Sezer M, Solmazgul E, Cerrahoglu K, et al. (2002) Hemostatic changes in active pulmonary tuberculosis. Int J Tuberc Lung Dis 6: 927-932.[Crossref]

11. Robson SC, White NW, Aronson I, Woollgar R, Goodman H, et al. (1996) Acute-phase response and the hypercoagulable state in pulmonary tuberculosis. Br J Haematol 93: 943-949.[Crossref]

12. Hoogerwerf JJ, de Vos AF, Levi M, Bresser P, van der Zee JS, et al. (2009) Activation of coagulation and inhibition of fibrinolysis in the human lung on bronchial instillation of lipoteichoic acid and lipopolysaccharide. Crit Care Med 37: 619-625.[Crossref]

13. Holmes CL, Russell JA, Walley KR (2003) Genetic polymorphisms in sepsis and septic shock: role in prognosis and potential for therapy. Chest 124: 1103-1115.[Crossref] 
14. Levi M, Schultz M, Van der Poll T (2013) Sepsis and thrombosis. Semin Thromb Hemost 39: 559-566.[Crossref]

15. Ogawa T, Uchida H, Kusumoto $Y$ (1991) Increase in tumor necrosis factor alphaand interleukin-6-secreting cells in peripheral blood mononuclear cells from subjects infected with Mycobacterium tuberculosis. Infect Immun 59: 30215.

16. Hussain R, Shiratsuchi H, Phillips M (2001) Opsonizing antibodies (IgG1) up-regulate monocytes proinflammatory cytokines tumor necrosis factor-alpha (TNF- $\alpha$ ) and IL-6 but not anti-inflammatory cytokine IL-10 in mycobacterial antigen-stimulated monocytes-implications for pathogenesis. Clin Exp Immunol 123: 210-218.

17. Valone SE, Rich EA, Wallis RS (1998) Expression of tumor necrosis factor in vitro by human mononuclear phagocytes stimulated with whole Mycobacterium bovis BCG and mycobacterial antigens. Infect Immun 56: 3313-3315.

18. Gauldie J, Northemann W, Fey GH (1990) IL-6 functions as an exocrine hormone in inflammation. Hepatocytes undergoing acute phase responses require exogenous IL-6. J Immunol 144: 3804-3808.

19. Kerr R, Stirling D, Ludlam CA (2001) Interleukin 6 and haemostasis. Br J Haematol 115: 3-12.[Crossref]

20. Kothari H, Rao LV, Vankayalapati R, Pendurthi UR (2012) Mycobacterium tuberculosis infection and tissue factor expression in macrophages. PLoS One 7: e45700.[Crossref]

21. Lyberg T, Closs O, Prydz H (1982) Effect of purified protein derivative and sonicates of Mycobacterium leprae and Mycobacterium bovis BCG on thromboplastin response in human monocytes in vitro. Infect Immun 38: 855-859.

22. Kuppalli K, Livorsi D, Talati NJ, Osborn M (2012) Lemierre's syndrome due to Fusobacterium necrophorum. Lancet Infect Dis 12: 808-815.[Crossref]

23. Gogna A, Pradhan GR, Sinha RS, Gupta B (1999) Tuberculosis presenting as deep vein thrombosis. Postgrad Med J 75: 104-105.[Crossref]

Copyright: (2016 Majeed T. This is an open-access article distributed under the terms of the Creative Commons Attribution License, which permits unrestricted use, distribution, and reproduction in any medium, provided the original author and source are credited. 